\title{
A Rare Complication Related with Oral Anticoagulant (Warfarin) Use: Diffuse Alveolar Hemorrhage (above 65 Years 4 Case Reports)
}

\section{Serap Duru*, Bahar Kurt, Merve Yumrukuz and Esra Erdemir}

Dışkapı Yıldırım Beyazıt Training and Research Hospital, Chest Diseases Clinic, Ankara, Turkey

\begin{abstract}
Diffuse alveolar hemorrhage (DAH) caused by immune and non-immune etiological factors, characterized by diffuse alveolar consolidation often presents with the clinical triad of dyspnea, hemoptysis, anemia, as a result of the distruption of the alveolocapillary membrane of the lung. We aimed to present above 65 yaears 4 cases followed in our clinic with diffuse alveolar hemorrhage as a rare complication of uncontrolled use of anticoagulant (warfarin) therapy. The cases was diagnosed as diffuse alveoler hemorrahage based on clinical, radiological and bronghoscopic data. After warfarin treatment was withdrawn, clinical and radiological signs recovered rapidly and the existent situation was thought to be DAH related with warfarin use after excluding other reasons. We think that the current cases is a rare disease of warfarin therapy leading to DAH.
\end{abstract}

\section{Introduction}

According to World Health Organization data, elderly population in the world, which constantly increases, is expected bo reach 1.2 billion by 2025 [1]. Due to chronic diseases occurring in this age group, the amount of drug used increases, hence they should be regularly monitorized. Diffuse alveolar hemorrhage, is a disorder developing due to immune and non immune etiological factors and characterized by shortness of breath, hemoptysia, anemia, and diffuse alveolar consolidation as a consequence of alveocapillary membrane damage in lungs. Its most common causes are collagen tissue diseases, infectious or toxic exposures, neoplastic diseases, and pulmonary thromboembolia [2]. In the elderly population, oral anticoagulants are the most commonly used drugs in order to prevent thromboembolic complications. During treatment with oral anticoagulants, various bleeding complications may occur during treatment with oral anticoagulants but the development of DAH is quite rare $[3,4]$. The aim of the present report was to present four cases over thae age of 65 who presented to meregency service consecutively due to DAH, which isa rare complication among warfarin associated hemorrhage.

\section{Case Report}

It was learned that 4 cases ( 2 females) over the age of 65 presenting to semergency service with the complaints of shortness of breath, cough and hemoptysia have used warfarin at an uncontrolled dose for the last three years. One used it for previous coronary bypass and atrial fibrillation while the other three for heart valve replacement. In physical examination, in one case with hypoxemic respiratory failure, blood pressure was found to be $100 / 70 \mathrm{mmHg}$, pulse $110 / \mathrm{min}$, respiration rate $30 / \mathrm{min}$ and body tempretaure 37 degree. In the examination of cardiovascular system, tachyarhtmia was seen and in respiratory sytem examination end inspiratory rales were present especially in infrasacpular regions. In artery blood gasa analysis, $\mathrm{pH}$ was found to be 7.40, $\mathrm{PaCO}_{2} 32.6 \mathrm{mmHg}, \mathrm{PaO}_{2} 55 \mathrm{mmHg}$ and oxygen saturation $88 \%$. Upper respiratory tract examination carried out by ear nose throat consultant yielded normal results. In the othre three cases, vital findings were as follows: increase in respiratory rate $(\geq 20 / \mathrm{min})$, tachycardia, body temperature 36 degree and in physical examination inspiratory rales in bilateral infrascapular regions. In all of the four cases, decrease in hemoglobin $(<10 \mathrm{gr} / \mathrm{dl})$, prolongation of prothrombin time (>10-14 second ) and increase in INR levels $(>3)$ were observed. Coagulation parameters was shown Table 1.

Other bicoenmiacl investigations were normal other than increase in serum creatinin level in one case. $(>1.1 \mathrm{mg} / \mathrm{d})$ tow cases who had respiratory failure and compliance problems could not undergo carbonmonoxide diffüsion test (DLCO). In two cases, increase in DLCO was established. Investitaions for carried out differential diagnosis of DAH. That is, cytoplasmic and perinuclear cytoplasmic antibody, antiglomerular basement membrane antibodies, antinuclear antibody, anti-ds DNA antibodies, complement level, rheumatoid factor, TORCH panel, serum D-dimer level, urinealysis and genetic examinations were found to be normal. When the history of being exposed to a toxic agent via inhalation, drugs used and smoking and drug habits were questioned, It was learned that two male patients had a smoking history of 15-20 pack-year, but did not have any clinical symptom of chronic airway disease. In order to rule out lung infections that can lead to the sameclinical picture, in sputum ARB. And gram positive staining was made with detection of no pathogens. In echocardiographic examination, it was established that left ventricle functions were adequate (EF 60\%) an done case had right atrial enlargement and minimal deficiency in tricuspid valve.

In posteroanterior chest graphies, bilateral widespread alveolar opacities were detected, which were mor pronounced in paracardiac and central areas (Figure 1). In thorax CT, pacthy ground glass infiltration areas accompanied by scattered nodular-acinar densities were seen in both lungs (Figure 2). Although normal bronchial system was observed in fiberoptic bronchoscopy (FOB), hemorragic foci were observed on mucosa (Figure 3) and hemosiderin-laden macrophages were proven in the pathological examination of the bronchoalveolar lavage (BAL).

In hemorragic lavage fluid obtained, hemosiderin laden macrohages were observed in addition to erithrocytes. In lavage fluid, $\mathrm{ARB}$ was negative and there was no growth in culture. In cytological examination, no malignant cells were observed. Following supportive treatment including oxygen administration, vitamin $\mathrm{K}$ replacement,

*Corresponding author: Serap Duru, Dışkapı Yıldırım Beyazıt Research and Education Hospital, Ankara, Turkey, Tel: +90 505 3124191; E-mail: akcalis@hotmail.com

Received October 21, 2014; Accepted July 02, 2015; Published July 07, 2015

Citation: Duru S, Kurt B, Yumrukuz M, Erdemir E (2015) A Rare Complication Related with Oral Anticoagulant (Warfarin) Use: Diffuse Alveolar Hemorrhage (above 65 Years 4 Case Reports). J Pulm Respir Med 5: 268. doi:10.4172/2161105X.1000268

Copyright: () 2015 Duru S, et al. This is an open-access article distributed under the terms of the Creative Commons Attribution License, which permits unrestricted use, distribution, and reproduction in any medium, provided the original author and source are credited. 
Citation: Duru S, Kurt B, Yumrukuz M, Erdemir E (2015) A Rare Complication Related with Oral Anticoagulant (Warfarin) Use: Diffuse Alveolar Hemorrhage (above 65 Years 4 Case Reports). J Pulm Respir Med 5: 268. doi:10.4172/2161-105X.1000268

Page 2 of 3

\begin{tabular}{|c|c|c|c|c|}
\hline Variables & Case 1 & Case 2 & Case 3 & Case 4 \\
\hline White blood cell (/ul) & 11,800 & 10,200 & 9,700 & 8,300 \\
\hline Hemoglobin (mg/dl) & 8.4 & 8.9 & 9.4 & 7.9 \\
\hline Hematocrit (\%) & 28 & 29 & 30 & 31 \\
\hline Platelet count (/ul) & 224,000 & 211,000 & 167,000 & 191,000 \\
\hline PT; second (INR) & $65(6.5)$ & $51(4.4)$ & $46(5.1)$ & $73(6.9)$ \\
\hline
\end{tabular}

PT: Prothrombin Time, INR: International Normalized Ratio.

Table 1: Coagulation parameters for diffuse alveolar hemorrhage cases.

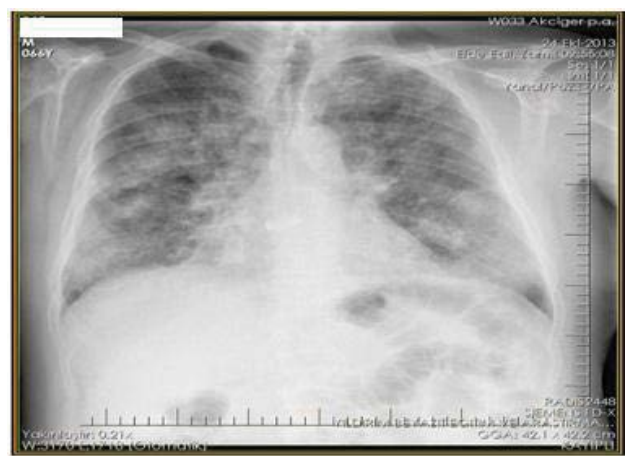

Figure 1: Posteroanterior lung graphy, widespread patched ground glass infiltrations in both lungs (Case 1).

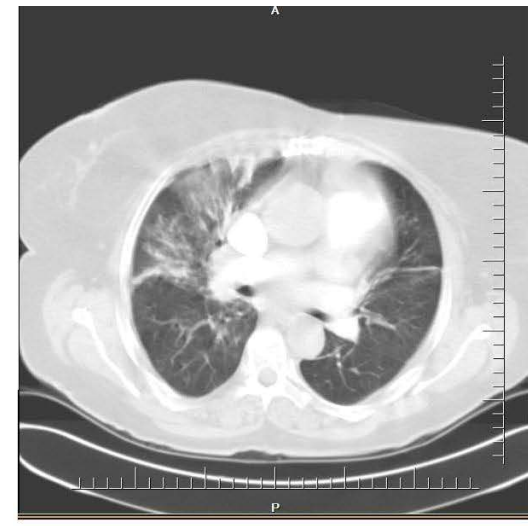

Figure 2: Widespread increase in alveolar density in the computerized tomography section (Case 2).

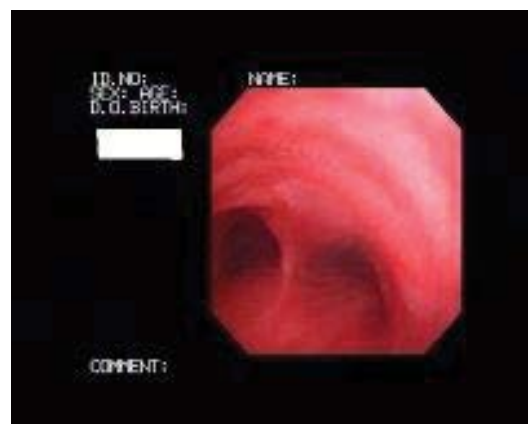

Figure 3: Fiberoptic broncoscopy image. All mucous with odema and hemorragic foci in the mucosa of entrance to upper lobe of lung (Case 2). and erithrocyte suspension and discontinuation of warfarin, clinical and radiological findings rapidly improved and our cases were discharged uneventfully.

\section{Discussion}

Diffuse alveolar hemorrhage complicating warfarin therapy may be a high mortality rate. Diffuse alveolar hemorrhage, which does not have s specific laboratory anc clinic diagnosis method, leads to a clinical picture ranging from cough, hemoptysia, shortness of breath to repiratory failure particularly in elderly patients. When this clinical picture is observed in patients on warfarin and infiltrations are detected in direct lung graphy. Diffuse alveolar hemorrhage should be among infiltrative lung diseases that should be kept in mind in differential diagnosis [5]. Of our cases, consistent with this clinical spectrum, cough, hemoptysia and breathlessness was found in three, while in one additionally respiratory failure was seen.

In DAH, definitive diagnosis is made by lung tissue biopsy guided by fiberoptic bronchoscopy. Bronchoscopic biopsy may have risk of fatality due to excessive mucosal hemorragia and severe respiratory failure [6]. Our purpose of bronchoscopy is primarily to see the intraalveolar blood, exclude endobronhial lesion and infection. In this case, the detection of hemosiderin laden alveolar macrophages in BAL with hemorrhagic appearance supports the diagnosis. Actually, the appearance of hemosiderin laden alveolar macrophages in our cases in BAL suggested the diagnosis of DAH.

There are many reason in DAH etiology. Among collagen tissue diseases, Wegener granülomatosis [7,8], systemic lupus erythematosus $[9,10]$ and Goodpasture syndrome [11], give rise to DAH owing to immun deposits in alveoler intertsium and intra-alveolar blood vessels. In addition, drugs such as cocain, difenylhidantoin and leflunomid may lead to DAH [12]. We investigated other etiologic factors and serum levels of collagen tissue marker (C-ANCA, P-ANCA, ANA and anti dsDNA) were analyzed. We did not find any problem for DAH in our cases. It is determined that the clinical picture in our cases is that of DAH which occurs rarely without any systematic involvement other than pulmonary involvement.

Warfarin is a commonly prescribed anticoagulant all over the world. Diffuse alveolar hemorrhage associated with warfarin was first described by Brown et al. [13]. Subsequantly, limited number of cases have been presented $[4,14]$. Therefore, we belived that our series of four cases may contribute the literature regarding this subject. In a previous study, it was reported that of all cases followed in hospital with side effects of drugs, $10 \%$ was associated with warfarin $[15,16]$. Care should be exercised in the follow up patients on warfarin and it should be borne in mind that, it may lead to DAH, albeit rarely, which has high mortality unless diagnosed and treated early.

\section{Conclusion}

Diffuse alveolar hemorrhage is a life threatening complication which may develop due to many etiologic factors. World population is getting older and the elderly living alone is increasing in all over the world. So it is difficult to track medication use in the elderly. In warfarin associated DAH cases, especially elderly cases who regularly used the drug should be warned against the risk of hemorrhage and should be regularly monitorized by clinicians. Early diagnosis is very important in DAH. The diagnosis must be clinically and radiologically and bronchoscopy.

\section{References}

1. World Health Organization (WHO).Elder maltreatment. 
Citation: Duru S, Kurt B, Yumrukuz M, Erdemir E (2015) A Rare Complication Related with Oral Anticoagulant (Warfarin) Use: Diffuse Alveolar Hemorrhage (above 65 Years 4 Case Reports). J Pulm Respir Med 5: 268. doi:10.4172/2161-105X.1000268

2. Ioachimescu OC, Stoller JK (2008) Diffuse alveolar hemorrhage: diagnosing it and finding the cause. Cleve Clin J Med 75: 258, 260, 264-265 passim.

3. Lee JH, Kim SW (2013) Successful management of warfarin-exacerbated diffuse alveolar hemorrhage using an extracorporeal membrane oxygenation. Multidisciplinary Respiratory Medicine 8: 16.

4. Erdogan D, Kocaman O, Oflaz H, Goren T (2004) Alveolar hemorrhage associated with warfarin therapy: a case report and literature review. Int J Cardiovasc Imaging 20: 155-159.

5. Schwarz MI, Cherniack RM, Talmadge E, King JR (2000) Diffuse Alveolar hemorrhage and other rare infiltrative disorders. In: Murray JF, Nadel JA (eds) Textbook of Respiratory Medicine. 3rd ed. W.B. Saunders Company 733-751.

6. Thomas JK, Jayaprakash K, Misiriya KJ, Khadar SA, Pappachan JM (2008) Catastrophic pulmonary alveolar hemorrhage complicating warfarin therapy. $J$ Assoc Physicians India 56: 34.

7. Macri A, Stoica R, Ion I, Dănilă E, Tănăseanu S (2007) [Wegener granulomatosis with severe alveolar hemorrhagic syndrome]. Pneumologia 56: 137-141.

8. Cordier JF, Cottin V (2011) Alveolar hemorrhage in vasculitis: primary and secondary. Semin Respir Crit Care Med 32: 310-321.

9. Santos BH, Santos RR, Santos CF, Kakehasi AM, Von Tiesenhausen HA (2004) Pulmonary hemorrhage as a manifestation of systemic lupus erythematosus.
Rev Hosp Clin Fac Med Sao Paulo 59: 47-50.

10. Lara AR, Schwarz MI (2010) Diffuse alveolar hemorrhage. Chest 137: 11641171.

11. Panek A, Walatek B, Sułowicz W (2013) [Goodpasture’s syndrome--disease of many faces]. Przegl Lek 70: 218-223.

12. Waness A, Aldabbagh T, Harakati M (2009) Diffuse alveolar haemorrhage secondary to warfarin therapy for atrial fibrillation: a case report and literature review. BMJ Case Rep 2009.

13. Brown OL, Garvey JM, Stern CA (1965) Roentgenogram of the month. Dis Chest 48: 525-526.

14. Finley TN, Aronow A, Cosentino AM, Golde DW (1975) Occult pulmonary hemorrhage in anticoagulated patients. Am Rev Respir Dis 112: 23-29.

15. Pirmohamed M, James S, Meakin S, Green C, Scott AK, et al. (2004) Adverse drug reactions as cause of admission to hospital: prospective analysis of 18 820 patients. BMJ 329: 15-19.

16. Burmester JK, Berg RL, Glurich I, Yale SH, Schmelzer JR, et al. (2011) Absence of novel CYP4F2 and VKORC1 coding region DNA variants in patients requiring high warfarin doses. Clin Med Res 9: 119-124. 